\title{
МАТЕРИАЛЫ ИТОГОВОЙ КОНФЕРЕНЦИИ МОЛОДЬХ УЧЕНЫХ МГМСУ ИМ. А.И. ЕВДОКИМОВА, 2013 ГОД
}

\author{
Авторы: \\ С.Д. ЛЕОНОВ, Д.Ю. АГИБАЛОВ, Д.А. АСТАХОВ, В.С. ЧУГУНОВ, Е.С. ЛЫТАСОВА, М.М. ЭЛЬДЕРХАНОВ, \\ А.М. ПЕРЕВЕДЕНЦЕВА, Е.К. ОСИПОВА, А.О. СМОЛЬСКИЙ, Г.Г. КИМ, И.А. КУРГАНОВ, М.Ш. МАМИСТВАЛОВ, \\ О.А. АГАФОНОВ, Ю.А. МЕРКУРЬЕВА, В.В. ЩЕРБАЧЁВ, А.М. БЕЛОГЛАЗОВА
}

С.Д. ЛЕОНОВ, Д.Ю. АГИБАЛОВ, Д.А. АСТАХОВ, B.С. ЧУГУНОВ, кафедра хирургии ФПДО, лаборатория минимально инвазивной хирургии, НИМСИ МГМСУ им. А.И. Евдокимова, НИИ клинической хирургии ФНКЦ ФМБА РОсСии

ИЗМЕРЕНИЕ ЭЛЕКТРИЧЕСКОГО ИМПЕДАНСА ПЕЧЕНИ В УСЛОВИЯХ ОБШИРНОЙ ЕЕ РЕЗЕКЦИИ В ЭКСПЕРИМЕНТЕ

Цель работы. Оценка полного электрического сопротивления (импеданса) паренхимы печени в динамике после ее обширной резекции.

- Материалы и методы. Исследование проведено на 27 белых лабораторных крысах линии Vistar обоего пола массой 180-230 г, которым под эфирным наркозом выполняли лапаротомию и измеряли импеданс печени. Затем проводили обширную резекцию исследуемого органа (до 70\%) и повторно измеряли импеданс паренхимы оставшейся доли печени, далее производили ревизию и ушивание брюшной полости. Спустя 72 ч выполняли релапаротомию и измеряли электрический импеданс паренхимы печени. Животных выводили из эксперимента и отправляли на гистологическое исследование фрагмент печени.

Инвазивную биоимпедансометрию проводили с помощью биполярных игольчатых электродов и оригинального устройства для измерения полного электрического сопротивления биологических тканей - BIM-II (Патент РФ № 2366360). Измерение осуществляли на частоте 2 кЦц и напряжении менее 1 вольта.

Результаты и их обсуждение. В послеоперационном периоде летальность составила 52\% (14 животных).

Электрический импеданс интактной печени был равен $3,18 \pm 0,12$ кОм $(\mathrm{n}=27)$. После обширной резекции исследуемый показатель у 20 крыс несколько уменьшился и в среднем составил $3,04 \pm 0,17$ кОм $(\mathrm{n}=27$, различия недостоверны, $\mathrm{p}>0,05)$, что, возможно, связано с увеличением кровотока в оставшейся доле печени.

Через 72 ч после оперативного вмешательства электрический импеданс паренхимы печени достоверно увеличивался до 4,00 $\pm 0,2$ кОм ( $\mathrm{n}=13, \mathrm{p}<0,05)$. При гистологическом исследовании у всех выживших животных развивалась жировая дистрофия печени различной степени выраженности, что и повлияло, по нашему мнению, на увеличение электрического импеданса исследуемого органа.

Таким образом, показатели электрического импеданса печени отражают изменения функциональной активности ее паренхимы и могут быть использованы для разработки диагностических технологий в хирургической гепатологии.

E.C. ЛЫТАСОВА, кафедра факультетской хирургии №1, НИМСИ МГМСУ им. А.И. Евдокимова, НИИ клинической хирургии ФНКЦ ФМБА РОссии

РАЗРАБОТКА И КЛИНИЧЕСКАЯ АПРОБАЦИЯ МОДУЛЯ EORTC QLQ-PRT23 ДЛЯ ОЦЕНКИ КАЧЕСТВА ЖИЗНИ БОЛЬНЫХ ЛУЧЕВЫМ РЕКТИТОМ

Одно из ведущих мест в комбинированном и комплексном лечении больных злокачественными новообразованиями занимает лучевая терапия. Вопросу лечения лучевых повреждений прямой кишки, реабилитации и оценке качества жизни (КЖ) онкологических больных, перенесших лучевую терапию на органы малого таза как этап комбинированного и комплексного лечения, в настоящее время отводится значительное место. Целью многочисленных рандомизированных исследований является определение прогностического значения показателя КЖ для оценки эффективности противоопухолевой терапии, толерантности больного к лечению, выживаемости.

Среди способов оценки качества жизни наиболее общеприняты и распространены опросники, заполняемые больными. Имеется ряд опросников, применяемых в онкологии. Широкое распространение получили два из них: американский опросник FACT-G (Functional Assessment of Cancer Therapy-General) и европейский - EORTC QLQ-C30 (Quality of Life Questionnary-Core 30 of European Organization for Research and Treatment Cancer).

Опросник EORTC QLQ-C30 используется в многоцентровых рандомизированных исследованиях в Европе, Канаде, а также 
в ряде протоколов в США. На основании оценки КЖ, проведенной самим больным, можно получить интегральноцифровую характеристику состояния здоровья человека. Методологическая основа, на которой базируется опросник, включает следующие положения: специфичность, многомерность (наличие нескольких шкал, характеризующих КЖ), возможность заполнения опросника самим больным, применимость к различным культурам. Современная версия EORTC QLQ-C30 включает 30 вопросов и состоит из 5 функциональных шкал, 3 шкал симптоматики, шкалы общего КЖ и одиночных пунктов. Опросник является модульным, т. е. в основу положен модульный подход, согласно которому имеется базовый опросник. К базовому опроснику может быть добавлен модуль - несколько дополнительных вопросов, специфичных для того или иного вида опухоли или программы лечения.

Модуль EORTC QLQ-PRT23 (разработанный для оценки КЖ больных, перенесших лучевую терапию как этап лечения рака прямой кишки, анального канала, предстательной железы, шейки и тела матки) находится на IV этапе исследования (анкеты недоступны для общего пользования). Четвертая фаза исследования включает перевод модуля с последующим использованием у больных острым и хроническим постлучевым проктитом. Опыт и практика онкологов и гастроэнтерологов показывает, что пациентам бывает трудно сформулировать жалобы, вызванные лучевым ректитом (как последствия проведенной ранее лучевой терапии), в связи с чем и был разработал модуль EORTC QLQ-PRT23. Нами проведено инициативное исследование совместно с QUALITY OF LIFE GROUP, в ходе которого, согласно руководству, происходил процесс перевода. В настоящий момент проводится пилотное тестирование модуля EORTC QLQPRT23 у больных, перенесших лучевую терапию на органы малого таза, как элемент противоопухолевого лечения на базе колопроктологического (онкологического) и радиологического отделения НУ3 «ЦКБ №2 им. Н.А. Семашко» ОАО РЖД. После обобщения результатов пилотного исследования и обсуждения с координаторами EORTC группы модуль EORTC QLQ-PRT23 может быть использован у больных острым и хроническим лучевым проктитом с целью оценки качества жизни.

М.М. ЭЛЬДЕРХАНОВ, кафедра хирургических болезней и клинической ангиологии, Московский государственный медико-стоматологический университет им. А.И. Евдокимова МИНИИНВАЗИВНЫЕ ВМЕШАТЕЛЬСТВА У БОЛЬНЫХ СТАРЧЕСКОГО ВОЗРАСТА С МЕХАНИЧЕСКОЙ ЖЕЛТУХОЙ

Механическая желтуха - тяжелое заболевание вследствие непроходимости желчных протоков. Причинами, вызывающими непроходимость желчных путей, являются желчные камни и стриктуры холедоха, злокачественные опухоли.

При запущенной механической желтухе, особенно у лиц пожилого возраста на фоне тяжелых сопутствующих заболеваний, в клинику внедряются малоинвазивные технологии.

Цель работы. Улучшение результатов лечения больных с механической желтухой путем оптимизации алгоритма диагностики, применения малоинвазивных технологий и этапного способа хирургического лечения.

Материалы и методы. Малоинвазивные вмешательства при механической желтухе выполнены 146 больным старческого возраста. Мужчин было 62, женщин - 84.

- Результаты. При обследовании у 85\% больных имелись от 5 до 6 сопутствующих заболеваний, что дает основание отнести полиморбизм к наиболее существенным клиническим особенностям при механической желтухе у лиц преклонного возраста. Болышинство больных (78,5\%) с механической желтухой госпитализированы по экстренным показаниям.

В связи с выраженностью и степенью декомпенсации сопутствующих заболеваний 76\% больных сразу госпитализированы в отделение реанимации и интенсивной терапии, где проводилось интенсивное лечение и обследование.

Тяжесть больных: по билирубину - до 100 мкмоль/л, 100-200 мкмоль/л, 200-400 мкмоль/л, 400 мкмоль/л; тяжесть по APACHE - II; тяжесть по эндотоксикозу по В.К. Гостищеву.

По стабилизации гемодинамики первым этапом в комплексе лечения выполняли холецистостомию под УЗ наведением. Эта манипуляция выполнена 43,8\% больных при синдроме Курвуазье и холедохолитиазе. Положительная динамика отмечена у 85\% больных. По улучшению состояния выполнен II этап - холецистэктомия через минидоступ, лапароскопически или обычным доступом и холедохолитотомия, при опухоли - билиодигестивный анастоMO3.

Ретроградная панкреатохолангиография (РПХГ) и папилосфинктеротомия (ПСТ) выполнена в срочном порядке 51,2\% больных, с удалением камней 30\%. Конкременты не удалены у 5,1\% больных (размеры более 37 мм). Этой группе больных была выполнена открытая операция из минидоступа под спинальной анестезией. Произведена холецистэктомия, холедохотомия, удалены конкременты и выполнено дренирование по Керу.

Основная группа больных (81\%), которым были выполнены этапные вмешательства, была оперирована в отсроченном периоде, после стихания острых явлений и эндотоксикоза, а также снижения полиорганной недостаточности. Летальных исходов в этой группе больных не было.

- Выводы. Показаниями к малоинвазивным вмешательствам на внепеченочных желчных протоках при механической желтухе является необходимость декомпрессии желчных протоков как первый подготовительный этап к радикальной операции при опухолевом поражении или рубцовых стриктурах и как окончательный вариант лечения при метастатических процессах в воротах печени, печеночнодвенадцатиперстной связке, склерозирующих поражениях протоков.

Малоинвазивные операции являются альтернативой традиционным операциям при механической желтухе любого 
генеза и уровня обструкции желчных протоков. Как метод временной или окончательной декомпрессии желчных путей и как метод подготовки к радикальной операции.

А.М. ПЕРЕВЕДЕНЦЕВА, кафедра общей хирургии лечебного факультета, ГБОУ ВПО «Московский государственный медико-стоматологический университет им. А.И. Евдокимова» Минздрава России

\section{МИНИМАЛЬНО ИНВАЗИВНЫЕ МЕТОДЫ ЛЕЧЕНИЯ КИСТ ПОДЖЕЛУДОЧНОЙ ЖЕЛЕЗЫ}

Актуальность. В последние годы отмечается неуклонный рост количества больных с тяжелыми формами острого и хронического панкреатита. Параллельно этому увеличилось число больных с тяжелыми деструктивными поражениями поджелудочной железы и пациентов с кистозными образованиями поджелудочной железы.

- Цели и задачи. Оценить эффективность консервативных миниинвазивных методов лечения кист поджелудочной железы.

- Материалы и методы. Наружное чрескожное чреспеченочное дренирование кист поджелудочной железы под контролем КТ выполнено у 22 пациентов - сотрудников железнодорожного транспорта с кистами поджелудочной железы (15 мужчин, 7 женщин) в возрасте от 32 до 54 лет, у 15 из них кисты носили постнекротический характер и у 7 кисты явились истинными, впервые выявленными. Пациентам устанавливались дренажи с диаметром катетера премущественно 8-8,5 Ф, при больших постнекротических кистах до 16 Ф. В послеоперационном периоде всем больным проводилась инфузионная и антибактериальная терапия, осуществлялся УЗ- и КТ-контроль. Повторная госпитализация через 3 мес., для контрольного обследования: КТ-контроль, УЗИ-контроль, фистулография для решения вопроса об удалении дренажа.

Результаты. При выявлении рубцевания кисты дренаж удалялся (15 пациентов, 68,2\%). При отсутствии признаков рубцевания производилось склерозирование кисты полимеризующимся клеем (3 пациента, 13,6\%). В случае обнаружения сообщения кисты с главным панкреатическим протоком (в 4 случаях, 18,2\%) удаление дренажа было отсрочено еще на 3 мес., в последующем у 2 пациентов достигнуто рубцевание свища. 1 пациенту выполнена операция в объеме продольной панкреатоеюностомии, 1 пациенту с рецидивирующим характером течения заболевания выполнена эндоскопическая цистогастростомия. Все пациенты с истинными впервые выявленными кистами поджелудочной железы успешно вернулись к работе.

Выводы. Чрескожное чреспеченочное дренирование под КТ-контролем (или УЗ-контроль) является альтернативным методом открытым и эндоскопическим способам лечения больных с кистами поджелудочной железы. Метод сочетает малую травматичность, визуальный контроль, возможность морфологической и бактериологической верификации диагно3а.
Е.к. ОСипОВА, кафедра общей хирургии лечебного факультета, ГБОУ ВПО «Московский государственный медикостоматологический университет им. А.И. Евдокимова» Минздрава России

\section{ОПЫТ ЛЕЧЕНИЯ РАКА КУЛЬТИ ЖЕЛУДКА}

В ОКД №1 с 1998 по 2012 г. наблюдались 6 больных с диагнозом рака культи желудка; в анамнезе перенесли резекцию желудка по поводу язвы желудка 5 пациентов и 1 пациент по поводу ожогового стеноза. Среди больных 5 мужчин и 1 женщина в возрасте от 64 до 75 лет. Сроки развития рака в культе желудка варьировали от 10 до 30 лет: у 4-х пациентов - до 15 лет, у 5-го - через 20 лет, у 6-го - через 30 лет. Диагноз во всех случаях установлен эндоскопически, подтвержден гистологическими исследованиями биоптата из опухоли. В 5-ти случаях аденокарцинома (в 2-х высокодифференцированная, в 2-х - умеренно дифференцированная, в 1-м - низкодифференцированная), в 1-м случае перстневидноклеточный рак. В 1-м случае больной направлен на химиотерапевтическое лечение из-за распространенности процесса. У 2-х больных выполнена эксполиативная лапаротомия в связи с местной распространенностью процесса. В 3-х случаях произведена радикальная операция в объеме экстирпации культи желудка. Больные, ранее перенесшие резекцию желудка по поводу неопухолевой патологии, через 15 лет составляют группу риска в связи с возможностью развития рака культи желудка.

А.о. СМОЛЬСКИЙ, ГБУЗ «ОКД №1» Департамента здравоохранения г. Москвы, кафедра общей хирургии лечебного факультета, ГБОУ ВПО «Московский государственный медико-стоматологический университет им. А.И. Евдокимова» Минздрава России

\section{полипЫ толстой кишки}

В отделении колопроктологии ДКБ им. Н.И. Семашко на ст. Люблино с 01.11.12 по 28.02.13 с диагнозом «полип толстой кишки» находилось двенадцать пациентов в возрасте от 50 до 80 лет. Распределение по локализации было следующее: прямая кишка (4), сигмовидная кишка (6), ободочная кишка (2). Из них семь женщин и пять мужчин. Диагноз был установлен при проведении колоноскопии, которая, в свою очередь, в восьми случаях из двенадцати была сделана намеренно пациентам, по рекомендации специалиста, после предъявления жалоб. Всем двенадцати пациентам была произведена эндоскопическая полипэктомия с направлением послеоперационного материала на клиническое гистологическое исследование. Из них одиннадцать - доброкачественные и один с признаками высокодифференцированной аденокарциномы. У пациента возраста 55 лет с признаками высокодифференцированной аденокарциномы при ФКС инвазии основания полипа не выявлено. Планируется динамическое наблюдение. Сравнительный анализ методов лечения холедохолитиаза у пациентов с тяжелой сопутствующей патологией. 
г.г. ким, кафедра общей хирургии лечебного факультета, ГБОУ ВПО «Московский государственный медико-стоматологический университет им. А.И. Евдокимова» Минздрава России

Сравнительный анализ методов лечения холедохолитиаза у пациентов с тяжелой сопутствующей патологией

Актуальность проблемы. Проблема диагностики и лечения холедохолитиаза остается актуальной и по сегодняшний день, т. к. большинство пациентов этой группы относится к категории пожилого и старческого возраста.

Цель работы. Оценка эффективности различных методов лечения холедохолитиаза у пациентов с взаимоотягощающей сопутствующей патологией.

- материалы и методы. Нами проведен ретроспективный анализ 52 историй болезни пациентов с желчнокаменной болезнью, осложненной холедохолитиазом, находившихся на лечении в НУЗ ДКБ им. Н.А. Семашко на станции Люблино в период с мая 2007 по октябрь 2012 г. Распределение пациентов в нашем исследовании по полу составило: мужчин 13 (25\%), женщин 39 (75\%). Возраст больных составил от 20 до 86 лет, средний возраст составил 57 лет. Пациенты с отягощенной сопутствующей патологией распределялись по анестезиологическому риску по шкале ASA II-III класса.

Из сопутствующей патологии у 29 больных выявлена ИБС: гипертоническая болезнь; у 6 пациентов ожирение 2-3 ст.; в 3-х случаях ОНМК в анамнезе; МКБ, хроническим пиелонефритом страдали 4 пациента; аневризма брюшного отдела аорты наблюдалась в 1 случае; у 1 пациентки ранее было выполнено аортально-митральное протезирование; сахарный диабет тяжелого течения выявлен в 3-х случаях.

В зависимости от метода лечения холедохолитиаза пациенты распределены следующим образом: больные, которым выполнялась ЭРХПГ с ПСТ и одномоментной литэкстракцией -22 пациента (42\%); ЭРХПГ и ПСТ с механической литотрипсией - 5 пациентов (10\%); ЭРХПГ+ПСТ с дистанционной ударно-волновой литотрипсией (ДУВЛ) выполнена 6 больным (12\%), дренирование желчевыводящих протоков под контролем КТ по Сельдингеру - 7 пациентов (13\%); операция в объеме: холецистэктомия, холедохолитотомия, дренирование по Керу выполнено 7 пациентам (13\%); холецистэктомия, холедохолитотомия, дренирование по Пиковскому - 1 пациенту (2\%) и в 1 случае (2\%) выполнена холецистэктомия, холедохолитотомия, холедоходуоденоанастомоз. 3-м пациентам (6\%) было выполнено ЭРХП, при котором конкрементов не обнаружено: в 1-м случае выявлена стриктура дистального отдела холедоха, в 1-м случае холангит, в 1-м случае сладж.

Результаты и обсуждения. Эндоскопическая ретроградная панкреатохолангиография с ЭПСТ выполнялась под внутривенной анестезией. Пациентам с тяжелыми сопутствующими заболеваниями анестезиологический риск (ASA IIIII класс), при крупном холедохолитиазе и невозможности выполнения литэкстрации или механической литотрипсии проводили ЭРХПГ с ПСТ и дистанционную ударно-волновую литотрипсию (ДУВЛ), добиваясь фрагментации конкремен- тов холедоха с последующим удалением фрагментов корзиной Дормиа.

Осложнения наблюдались в 10 случаях: в 2-х возникло кровотечение после ЭПСТ - остановлено эндоскопически с использованием аргон-усиленной коагуляции, в одном случае после лапароскопической холецистэктомии с дренированием холедоха по Пиковскому, потребовавшее релапароскопии и остановки кровотечения; три случая очагового панкреонекроза; у 3 пациентов острый отечный панкреатит и у 1 больного - гнойный холангит. В группе пациентов, отягощенных сопутствующей патологией, которым проведена дУВЛ с последующей экстракцией конкрементов, осложнений не наблюдалось.

- Выводы. Дистанционная ударно-волновая литотрипсия в сочетании с малоинвазивными эндоскопическими методиками может быть использована в комплексном лечении холедохолитиаза, особенно у пациентов пожилого и старческого возраста с тяжелой сопутствующей патологией.

И.А. КУРГАНОВ, М.Ш. МАМИСТВАЛОВ, О.А. АГАФОНОВ, ГБОУ ВПО МГМСУ им. А.И. Евдокимова Минздрава России, кафедра эндоскопической хирургии ФПдО

\section{ЭКСПЕРИМЕНТАЛЬНЫЙ ОПЫТ ВЫПОЛНЕНИЯ ГЕМИТИРЕОИДЭКТОМИИ ПОСРЕДСТВОМ АКСИЛ- ЛЯРНО-РЕТРОАУРИКУЛЯРНОГО ЭНДОХИРУРГИЧЕС- КОГО ДОСТУПА}

На сегодняшний день в хирургии щитовидной железы существуют две основные проблемы, которые обосновывают потребность в модификации стандартных оперативных методик и во внедрении эндохирургических технологий. В первую очередь, это сохраняющаяся на постоянном уровне частота развития тяжелых послеоперационных осложнений (парез голосовых связок и гипопаратиреоз). Вторая важная проблема - формирование на передней поверхности шеи рубца длиной 6-8 см, который не скрывается повседневной одеждой и вызывает неудовлетворенность многих больных проведенным вмешательством, обуславливая снижение уровня качества жизни пациентов.

- Цели исследования. Разработать методикуэндохирургического оперативного вмешательства на щитовидной железе, выполняемого посредством аксиллярно-ретроаурикулярного доступа. Изучить оптимальную оперативную технику, выявить уровень выполнимости и безопасности метода.

- Материалы и методы. Предложенная методика была опробована в экспериментальном исследовании на трупах (5 операций). Вмешательство осуществлялось посредством полностью эндоскопического, аксиллярно-ретроаурикулярного экстрацервикального доступа (заявка на выдачу патента РФ на изобретение №2012143342 «Способ эндовидеохирургического доступа к доле щитовидной железы») с последующим проведением гемитиреоидэктомии (заявка на выдачу патента РФ на изобретение №2012144497 «Способ эндохирургической гемитиреоидэктомии»). Было проведено 2 правосторонних и 3 левосторонних вмешательства. Операции 
Новое поколение справочников

для высоких стандартов врачебной практики

\section{ATJACb ЛЕКАРСТВЕННЫХ СРЕДСТВ}

\section{УНИКАЛЬНЫЕ ОСОБЕННОСТИ АТЛАСА}

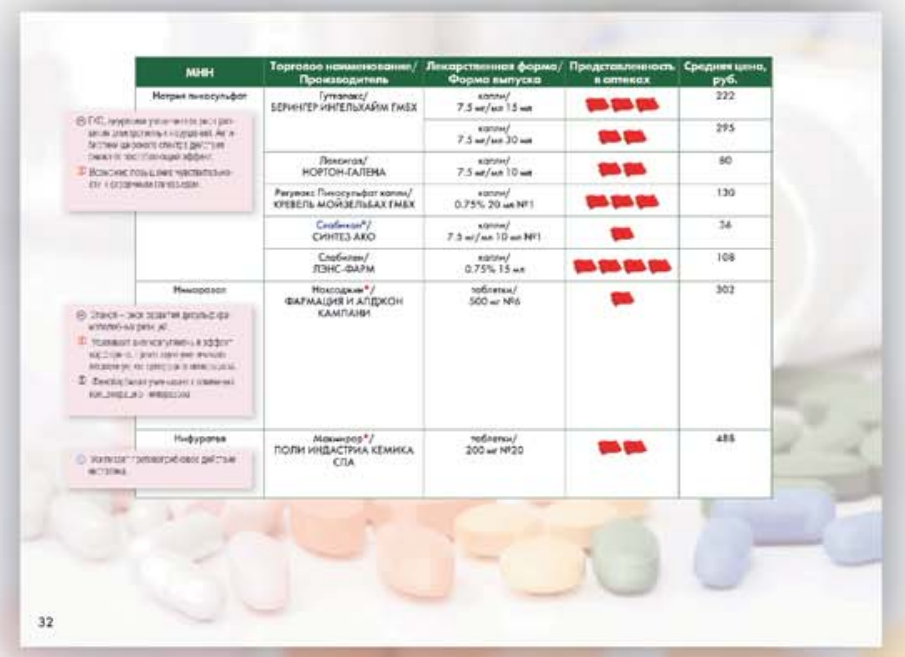

B 2012 году

были выпуцены Атласы

по специальностям:

- Кардиология

- Tepanug

- Урология

- Ревматология

- Бронхопульмонология и ЛОР

- Педиатрия
- Наличие всех ТН с высокой (более $40 \%$ ) представленностью в аптечной рознице

- Результаты маркетинговых исследований, включающие среднюю стоимость препарата в аптеке

- Визуализированные данные по взаимодействию лекарственных средств

- Широкий спектр медицинских направлений

- Удобная навигация, альбомный формат и качественная полиграфия

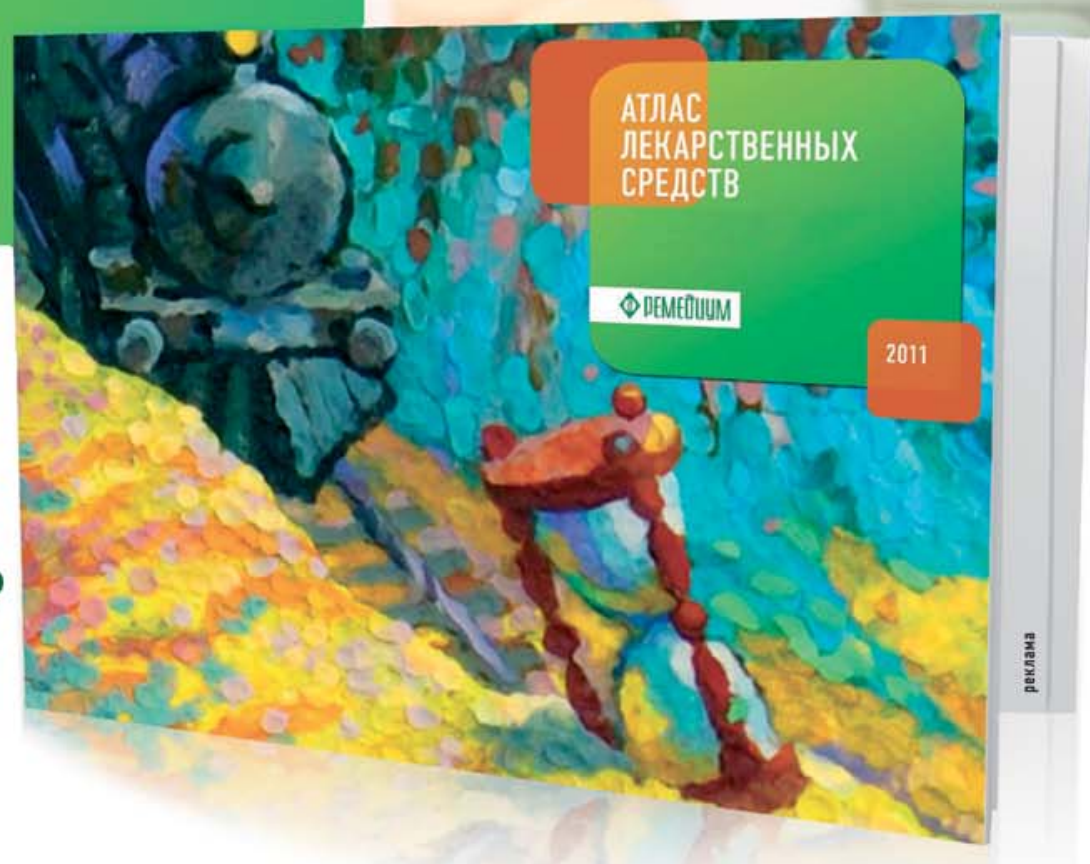


проводились в 5 этапов (осуществление кожного доступа; создание первичной полости; создание доступа к железе; гемитиреоидэктомия; экстракция препарата) с установкой 3 троакаров (двух в подмышечной впадине и одного по нижнему краю сосцевидного отростка височной кости на стороне операции). Троакар, введенный через ретроаурикулярный доступ, использовался не только для введения ассистирующего инструмента, но и для обзора операционного поля с другого угла зрения («вид сверху»). Давление инсуффлируемого газа поддерживалось на уровне 6-8 мм рт. ст. для предотвращения его распространения по клетчаточным пространствам и в средостение. Объем операции во всех случаях был равен гемитиреоидэктомии, что связано с техническими ограничениями данного вида доступа. В качестве основного инструмента для диссекции тканей использовались ультразвуковые ножницы.

- Результаты. Среднее время вмешательства в целом составило 113 (от 99 до 130) мин, причем на осуществление этапов было затрачено в среднем 8, 26, 31, 37 и 11 мин. Идентификация и сохранение обеих околощитовидных желез были достигнуты во всех 5 случаях. Возвратный гортанный нерв был визуализирован во время диссекции при проведении 4 операций из 5. Однако при дальнейшем анатомировании было подтверждено сохранение анатомической целостности нерва во всех случаях. Следует отметить, что применение «вида сверху» позволило уверенно визуализировать и идентифицировать низко расположенные анатомические образования, а также структуры в области латеральной поверхности железы и трахео-пищеводной борозды.

- Выводы. Проведение гемитиреоидэктомии посредством аксиллярно-ретроаурикулярного эндохирургического доступа является методологически и технически обоснованным. Рассматриваемая методика в эксперименте продемонстрировала свою выполнимость и безопасность и может быть рекомендована к дальнейшему клиническому применению.

Ю.А. МЕРКУРЬЕВА, Московский государственный медикостоматологический университет им. А.И. Евдокимова, кафедра психологического консультирования, психокоррекции и психотерапии

\section{НЕЙРОПСИХОЛОГИЧЕСКИЕ ОСОБЕННОСТИ И ОСОБЕННОСТИ ТЕЛЕСНОСТИ У ПОДРОСТКОВ С ИНТЕРНЕТ-ЗАВИСИМЫМ ПОВЕДЕНИЕМ}

Цель исследования. Изучение нейропсихологических особенностей у подростков с интернет-зависимым поведением, а также их нейропсихологических особенностей. Нами было обследовано 235 учащихся школ ЦАО г. Москвы, средний возраст 15,5. Далее по результатам методики «Шкала интернет-зависимости Чена» и экспертной оценки данная группа была поделена на две: экспериментальную и контрольную. В экспериментальную группу вошли 98 испытуемых, в контрольную - 100. Нейропсихологические особенности выявлялись путем проведения адаптированного нейропсихологического исследования для подростков (на основе Лурия-90). Данные, полученные по методике «шкала Чена», и показатели нейропсихологических профилей подростков были подвергнуты корреляционному анализу, который не выявил значимой корреляционной связи показателей ( $\mathrm{p} \leq 0,05)$, однако мы обращаем внимание на следующее: показатели функциональных нарушений правого полушария и межполушарных взаимодействий имеют тенденцию к корреляции. В ходе анализа различий выборок были выявлены следующие значимые различия: у подростков с интернетзависимым поведением отмечаются более высокие показатели нарушений пространственного праксиса, слухомоторных координаций, опосредованного запоминания, контроля и регуляции деятельности, внимания. При объединении показателей по локализации данных функций мы получили следующие индексы: 1) отражающий трудности передних отделов левого полушария; 2) отражающий трудности, связанные с задними отделами левого полушария; 3) отражающий правополушарные трудности. Далее был проведен анализ различий групп зависимых и условно здоровых. Итак, подростки с интернет-зависимым поведением значимо отличаются от условно здоровых по показателям функциональных нарушений пространственного праксиса, слухомоторных координаций, внимания, контроля и регуляции деятельности, а также опосредованного запоминания. Соотнося эти данные с локализацией функций, мы отмечаем функциональную слабость межполушарных комиссур и левой передней доли, кроме того, учитывая утомляемость, снижение концентрации внимания, можно говорить о слабости первого блока мозга. Важно отметить, что функциональная недостаточность межполушарных взаимодействий увеличивает нагрузку на первый и третий блоки мозга. Итак, мы можем провести параллель с особенностями интернет-деятельности: подростки могут использовать интернет как способ поддерживать активность, т. к. постоянное появление новых стимулов внешне регулирует концентрацию внимания, хотя в то же время это способствует еще большему истощению и утомлению.

Отдельная часть исследования была посвящена изучению сформированности образа тела у испытуемых в контрольной и основной группах. Данные группы были обследованы следующими методиками: тест на интернет-зависимость Чена (адаптация - В.Л. Малыгин, К.А. Феклисов), методика «Телесный образ я» (М. Feldenkreiz, адаптация - И.А. Соловьева), методика «Рисунок человека» (К. Маховер).

Корреляционный анализ результатов методики «Телесный образ я» и показателей выраженности интернет-зависимости показал наличие достоверной положительной корреляции. Качественный сравнительный анализ методик «Телесный образ я» и «Рисунок человека» обнаружил следующие символические особенности образа тела: в методике «Телесный образ я»: уменышение длины стопы - недостаточная устойчивость, потребность в опоре, отсутствие внутренней и/или внешней поддержки; удлинение шеи - блокирование и отделение эмоций от сознания; увеличение ширины и высоты головы - высокая значимость интеллекта в системе ценностей, гиперконтроль над телесными импульсами; уменышение длины руки - нарушения и проблемы общения, недоста- 
точная коммуникативная компетентность; преуменышение области от талии до промежности - тревога, относящаяся к сексуальности; в методике «Рисунок человека» отмечаются сходные символические особенности: проблемы опоры $80 \%$, отделение чувств и эмоций от сознания - 75\%, нарушение коммуникаций - 70\%, тревога в сексуальной сфере - 80\%, недифференцированность рисунка, наличие только границ - нарушение контакта с телом, отсутствие знаний о нем - 30\%.

Выводы. 1. Образ тела подростков, проявляющих паттерн интернет-зависимого поведения, искажен значимо больше, чем у группы здоровых подростков (54,7\%). 2. Образ тела подростков с интернет-зависимым поведением значимо менее дифференцирован по сравнению со здоровыми подростками. Особенности искажений образа тела у интернетзависимых подростков говорят о нарушении контакта эмоций, тела и сознания, проблемах в сфере общения, отсутствии опоры и уверенности, нарушении контакта со своими желаниями.

В.Л. МАЛЫГИН, д.м.Н., В.В. Щербачёв, Московский государственный медико-стоматологический университет, кафедра психоконсультирования, психотерапии и психокоррекции

\section{ХАРАКТЕРОЛОГИЧЕСКИЕ ОСОБЕННОСТИ УЧАСТНИКОВ СУБКУЛЬТУРЫ РОЛЕВЫХ ИГР}

В начале 1990-х гг. в различных городах России среди молодежи появилось новое увлечение - ролевые игры. Возникшие на волне культурных феноменов, пришедших с Запада, они были изначально проникнуты духом творчества и ухода от повседневности. В очень короткие сроки ролевые игры привлекли болышое количество заинтересованных, сформировавших вокруг своего увлечения субкультуру. Окружающий мир оказывал определенное давление, диктуя исключительно материальные ценности, вызывая у таких молодых людей стремление к побегу и протесту. Под влиянием этих стремлений ролевые игры и субкультура, принявшая самоназвание «ролевое движение», продолжали свое существование и развитие, пока не стали заметны на общественном уровне.

Оценки последовали самые разнообразные: от одобрения нового культурного феномена до открытой враждебности и подозрений в массовом психозе или особом виде сектантства. Этот вопрос остается дискуссионным до сих пор.

В настоящее время субкультура ролевых игр насчитывает несколько десятков тысяч участников по всей России и обрела признание на административном и культурном уровнях. Среди лиц, увлекающихся ролевыми играми, встречаются люди разных возрастов и социальных классов, условно здоровых и с обширными психологическими и социальными проблемами. Именно поэтому сейчас изучение ролевых игр и особенно их участников с психологической точки зрения является чрезвычайно актуальными.

В 2009 г. нами было проведено первое исследование личностных особенностей активных участников ролевых игр с целью выявления характерных закономерностей. В результате к настоящему моменту были сформулированы следующие гипотезы:

1) ролевые игры привлекают людей с особенным сочетанием личностных и характерологических черт;

2) участие в ролевых играх живого действия является проявлением психологической инфантилизации личности.

Для проверки данных гипотез были сформированы две группы испытуемых. Экспериментальная группа состоит из 24 человек в возрасте 19-25 лет, более двух лет участвующих в ролевых играх. Экспериментальная группа была набрана по личному знакомству и на интернет-форумах, посвященных ролевым играм. Контрольная группа состоит из 22 лиц того же возраста, никогда не участвовавших в ролевых играх.

Обе группы были исследованы следующими методиками:

1. «Опросник Шмишека» (SF, H. Schmieschek, адаптация В.М. Блейхера, Н.Б. Фельдмана).

2. Методика «Диагностика уровня субъективного контроля» (LCS, J.B. Rotter, адаптация Е.Ф. Бажина, C.A. Голынкиной, A.M. Эткинда).

3. Многофакторный личностный опросник Р. Кеттелла (в адаптации А.Н. Капустиной).

4. Методика исследования представлений о «» Т. Лири.

5. Тест Гилфорда «Социальный интеллект».

Полученные данные патохарактерологического опросника Шмишека позволяют квалифицировать три ведущих типа акцентуаций у активных участников ролевых игр Демонстративность, Экзальтированность и Циклотимность. Исходя из выявленного сочетания акцентуаций, можно отметить, что чрезмерно выраженными у активных участников ролевых игр являются те черты личности, которые связаны с эмоциональной сферой, высокой психологической лабильностью, а также гипертрофированной потребностью во внимании. Мы видим картину творческой, лабильной личности, акцентуированной в сторону эмоциональной сензитивности и поэтому крайне зависимой от окружающего мира личности. Ведущей акцентуацией черт характера является экзальтированность как необходимость в пассивном, созерцательном получении эмоций. Можно предположить, что сочетание этих качеств с потребностью во внимании, артистизмом и другими проявлениями демонстративности свидетельствует о поиске собственной идентичности через окружение. Данные многофакторного личностного теста Кеттелла позволяют сделать вывод о том, что активным участникам ролевых игр свойственна большая, в отличие от контрольной группы, сензитивность, потребность во внимании и склонность к уходу в фантазии (I+), а также пренебрежение правилами, ярче выраженное стремление к независимости (G-). Кроме того, выделяются значительно более выраженная подозрительность, недоверчивое отношение к окружающему социуму (L-) и внутренняя напряженность, раздражительность, предположительно детерминированная избытком побуждений, не находящих разрядки (Q4+).

Данный психологический профиль, учитывая наиболее выраженные типы акцентуаций, позволяет предположить, что активным участникам ролевых игр свойственен психологи- 
ческий инфантилизм, возвращающий их на подростковоюношескую стадию развития. Кроме того, тест на уровень субъективного контроля показал, что активные участники ролевых игр проявляют болышую, чем испытуемые контрольной группы, склонность к экстернальному локусу контроля, т. е. у них доминирует тенденция приписывать причины происходящего с ними внешним факторам (окружающей среде, судьбе, случаю или действиям других людей), снимая с себя любую ответственность. Особенно выделяются в этом отношении следующие сферы: общая сфера, сфера достижений и сфера производственных отношений.

Это также подтверждает предыдущие выводы о психологической незрелости, свойственной активным участникам ролевых игр, и позволяет предположить развитость такого механизма психологической защиты, как проекция.

Более четко этот факт проявляется в данных теста Лири. В нем значимые различия данных экспериментальной и контрольной групп выявлены в разделе Я-реальное, в шкалах III и IV - агрессивность и подозрительность соответственно. Можно проследить взаимосвязь между чертами подозрительности и агрессивности. Неуверенность в себе, детерминированная отсутствием четкой идентичности, вызывает защитную реакцию в виде направленной вовне агрессии, которая в свою очередь с помощью развитого механизма проекции, выявленного ранее, переносится на окружающий мир. Таким образом, порождается внутриличностный конфликт, не находящий разрешения и создающий напряжение. Вопрос влияния данного конфликта на адаптацию к социуму требует дальнейшего изучения, однако уже сейчас можно предположить, наличие дезадаптивного протеста. Противопоставление себя социуму, очевидно, способствует эскапизму (стремлению уйти от реальной действительности, общепринятых стандартов и норм общественной жизни в мир социальных иллюзий или в сферу псевдодеятельности, бегству в виртуальный мир.) Обобщая полученные данные и их интерпретацию, а также учитывая результаты выявления значимых различий в тесте Гилфорда, можно выдвинуть предположение, что активным участникам ролевых игр свойственен сниженный уровень социального ориентирования, обусловленный большей направленностью внимания на себя, чем на окружающий мир. Сложность в понимании и прогнозировании межличностного взаимодействия является фактором, способствующим социальной дезадаптации.

Подытоживая вышеизложенное, можно сформулировать следующие выводы.

1. Для участников ролевых игр характерен характерологический портрет, соответствующий старшему подростковому возрасту.

2. Им присуще тревожное, подозрительное и агрессивное отношение к окружающему социуму, предположительно детерминированное несформированностью устойчивой идентичности. Неуверенность в себе вызывает тревогу, в свою очередь порождающую агрессию как защитную реакцию.

3. Зависимость внутреннего состояния от внешнего мира и потребность во внимании фрустрируются тревожно- подозрительным восприятием окружающего социума, порождая внутриличностный конфликт, вызывающий не разряжающееся напряжение.

4. Можно предположить, что ролевые игры являются для их активных участников эскапистическим способом решения описанного выше внутриличностного конфликта, а также формой поиска идентичности.

А.М. БЕЛОГЛАЗОВА, Московский государственный медикостоматологический университет, факультет клинической психологиИ

\section{ВЗРОСЛАЯ ПРИВЯЗАННОСТЬ КАК ФАКТОР РОЛЕВЫХ, ЦЕННОСТНЫХ И АДАПТАЦИОННЫХ ХАРАКТЕРИСТИК ОБРАЗА СЕМЬИ В СУПРУЖЕСКИХ ПАРАХ}

В настоящее время возникла острая необходимость в новом изучении и описании того, что же такое семья, каковы представления супругов о ней, что именно необходимо для того, чтобы семейная система благополучно функционировала. Стабильность супружеских отношений уже не обеспечивается исключительно внешними, социальными факторами сейчас основной акцент сместился на психологическую составляющую брака. Супружеские отношения регулируются в первую очередь самими партнерами и в значительной степени зависят от их личностных особенностей.

Целью нашей работы стал анализ связи взрослой привязанности у супругов и ее согласованности с ценностными, адаптационными и ролевыми характеристиками образа семьи, а также удовлетворенностью браком. Мы руководствовались предположением о том, что привязанность и согласованность ее параметров в супружеских парах является фактором ценностных, адаптационных и ролевых характеристик образа семьи.

В ходе исследования были проверены следующие гипотезы: - о существовании взаимосвязей между ценностными, адаптационными и ролевыми характеристиками образа семьи как у каждого из супругов, так и внутри супружеской пары; - о существовании связей между надежностью, тревожностью и типом привязанности супругов, а также их согласованностью в паре, с одной стороны, и ценностными, адаптационными и ролевыми характеристиками образа семьи - с другой;

- о наличии связи удовлетворенности браком каждого из супругов, а также согласованности показателей удовлетворенности браком внутри пары с параметрами взрослой привязанности, ценностными, адаптационными и ролевыми характеристиками образа семьи.

Образ семьи является сложной, многоуровневой структурой, для описания которой необходимо изучение множества факторов. В центре внимания находится вопрос не столько о наличии, сколько о согласованности многих характеристик внутри супружеской пары (например, типа и параметров взрослой привязанности супругов, субъективной удовлетворенности браком, представлений о супружеских ролях и т. д.). 